\title{
Research on the Education Reform of Mechanical and Electrical Engineering Undergraduate Based on Self-exploration and Collaborative Learning under Virtual Simulation Experimental Platform
}

\author{
Xuan Sun*, Lieping Zhang, Qunying Zhang, Xianxuan Li \\ College of Mechanical and Control Engineering \\ Guilin University of Technology, \\ 12 Jiangan Road, Guilin, China \\ *Email: Sunxuan@glut.edu.cn
}

\begin{abstract}
This paper expounds the establishment of virtual simulation experimental teaching system for mechanical and electrical engineering major. Under the virtual simulation experimental teaching system, it carries on research of teaching methods and teaching modes for undergraduate experimental courses of mechanical and electrical engineering major, provides reference for self-exploration and collaborative learning of students in the reform of education and teaching methods, and cultivates innovative practical ability of students.
\end{abstract}

Keywords: Virtual simulation, innovative practice, self-directed collaborative learning, education reform

\section{INTRODUCTION}

Engineering innovation talents are essential on building an innovative country and implementing the strategies of developing China through science and education and strengthening the country through human resource development. The task of higher education is to train senior professionals with innovative spirit and practical ability, which is the need for social and economic development, the need for international competition, the need for the current state of education in China, and the need for individual university students to achieve growth and development. The transformation of China from big country with manufacturing to a great manufacturing power requires a large number of innovative mechanical and electrical engineering students with engineering practice capabilities. Meanwhile, enhancing the engineering practice ability of undergraduates and postgraduates in mechanical and electrical engineering is an important way to cultivate innovative talents. It is also an important issue that must be paid high attention to improve the quality of higher engineering education. How to improve the cultivation of engineering practice of university students and implement the reform of the talent cultivation model is an urgent problem in the current Chinese higher education, which is articularly important for local colleges and universities. For a long time, under the guidance of paying attention to theory and despising the practice in Chinese higher education, engineering literacy of engineering students is far from satisfying the status of great manufacturing power of China.

The continuous development and widespread application of modern information technology and network technology have had a profound impact on education and teaching, especially the impact on higher education. In the documents Several Opinions on Improving Education Quality and Rejuvenating Higher Education in Guangxi ([Guizhengfa 2013] No. 6) and Decision on Accelerating Reform and Innovation and Rejuvenating Education, People's Government of Guangxi Zhuang Autonomous Region specifically indicated that, "To promote the deep integration of modern information technology and education and promote the in-depth application of information technology in education and teaching", "All colleges and universities should speed up the digital transformation of courses and majors, innovate teaching and learning methods, enhance the level of personalized interactive teaching, and continuously improve the ability of teachers and researchers to use information technology to conduct scientific research." For each teaching model of engineering major, virtual simulation (reality) technology and curriculum integration and curriculum teaching have very close connection and inheritance. At the same time, it is a new type of teaching structure and method with relatively independent characteristics. It is a new method and new concept in education and teaching reform based on the development of computer technology and network communication technology. Use virtual simulation technology as a cognitive tool to promote students learning and engineering training, make full use of the learning environment provided by information technology such as exploratory learning, multiple interactions, online Q\&A, collaborative learning, and exploration learning [1], mobilize enthusiasm and initiative of the students, make every student get effective exercise in the fusion process of innovative thinking and practical ability. This is exactly what the innovative talents need to cultivate, and it will have a profound effect on modern education and future development of students.

In order to adapt the needs of the country for innovatiove talents and the reform of training model for exploratory innovative talents, construct an experimental teaching system and experimental teaching environment for the virtual simulation experiment platform, and strengthen self-inquiry and collaborative spirit and ability to innovate of the students. This article combines the Guangxi Higher Education Undergraduate Education Reform Project of autonomous region to carry out a 
"self-discovered collaborative learning learning teaching reform research and practice" work, and achieved good results, hoping to provide reference and new ideas for the implementation of similar projects.

\section{II.CONSTRUCTION OF VIRTUAL SIMULATION EXPERIMENTAL TEACHING SYSTEM}

In the detailed construction of experimental teaching system, a "Three levels, four modules, five integrations" virtual experimental teaching system is proposed. Specifically, it realizes the knowledge integration of the mechanical and electrical engineering major with the goal of improving capabilities, based on professional modules, and for application purposes [2]. The virtual experimental teaching system is shown in Figure 1.

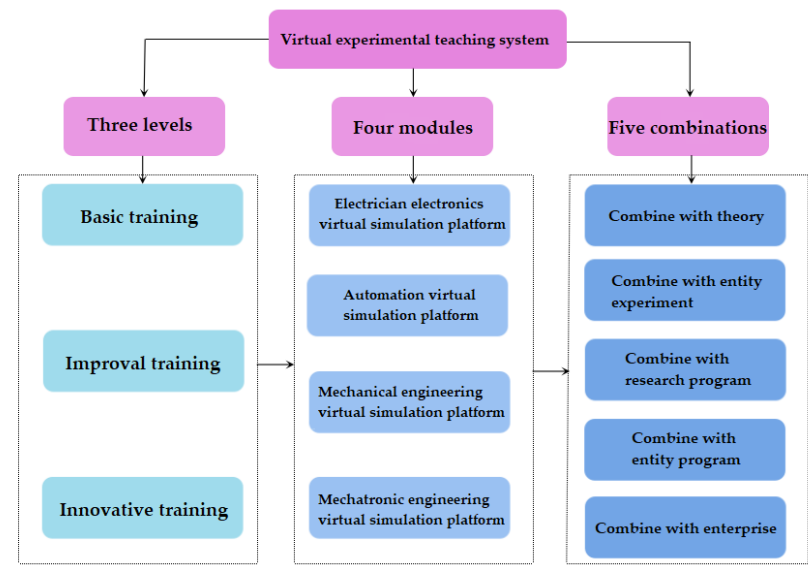

Fig.1 Virtual experimental teaching system

In the specific platform construction, we cooperated with Beijing Rainier Company to develop a virtual simulation teaching center portal site and a virtual simulation management and sharing platform. In the three core basic courses in automation major, electric circuits, analog electronics and digital electronics, Protel softeware can be used to simulate as well as Multisin simulation platform developed by NI company and related experiment bench entities. In major of Mechanical Manufacturing and Automation, Mechatronic Engineering, there are basic cartography courses such as AutoCAD. The college has a certification body authorized by the Education Management Information Center of the Ministry of Education. Students who pass the examination can be issued a "Three-dimensional CAD Engineer" certificate. Matlab software is typically used in professional courses of automation major. For process control systems, we have PCS7 simulation software developed by Siemens. For MCU courses have dedicated simulation software Protues. Virtual instrument simulation software from NI company are used for automatic test systems. Simulation sofewares of mechanics major are ANSYS and Admas. CAXA simulation software used in metalworking centers is dedicated for digital processing simulation design. The college also purchased virtual simulation teaching software Robot Studio for industrial robots, which supports off-line programming of mainstream industrial robots, can import 3D models and perform trajectory planning to be used for three undergraduate majors of Automation, Mechanical Manufacturing and Automation, and Mechatronic Engineering.

The software included in the above simulation teaching platform covers three basic trainings, improved training (professional comprehensive training), and innovative ability training. In the construction of the experimental platform, the college actively cooperates with enterprises to jointly develop experimental projects and equipments, focuses on the development of experimental projects and equipment with own characteristics. The teacher of automation major cooperated with Shenzhen Orwell Control Technology Co., Ltd. to develop a PLC-based industrial automation process control and integration experimental equipment based on virtual reality. The teacher of mechanics major cooperated with NI Corporation to develop an electromagnetic suspension rotor experiment based on PXI automatic testing. Monitoring station. The development of the above equipment to improve the construction of the platform and highlight its own characteristics.

\section{IMPLEMENTATIOIN OF TEACHING REFORM}

\section{A. General Ideas}

At present, the self-control ability of local college students is not strong, and the spirit of independent study, independent exploration, and teamwork learning is lacking. The purpose of this project is to combine classroom teaching, post-school and online teaching, offline self-learning, independent exploration, team collaborative learning. Use a virtual simulation experiment teaching platform to effectively guide students to learn in a self-directed collaborative approach. There are issues such as self-directed learning, self-discovery, and collaborative learning that have difficulty in measuring and evaluating direct indicators. In the teaching practice, we have used the online platform technology to construct a preliminary evaluation mechanism and incentive mechanism, effectively guiding students to explore collaborative learning independently. The teaching mode implemented by the virtual simulation experimental platform has the following features:

1) Combining virtual simulation experimental teaching platform with virtual simulation resources and laboratory physical entity equipment as the basis for students to independently explore collaborative learning.

2) The virtual simulation experiment teaching platform provides a wealth of teaching resources to achieve the combination of classroom teaching and after-school learning, online self-learning and offline collaborative exploration. The characteristic of the virtual simulation experiment teaching platform is to provide students with a basic platform. Students can use any time to learn online and offline.

\section{B. Reform of Teaching Method}

Based on the virtual simulation experimental teaching platform, the independent exploration of collaborative learning and teaching reform is based on the virtual 
simulation experimental teaching platform that combined with virtuality and reality, which makes the teaching methods have a basis for reform.

First of all, in the classroom teaching of the course, theoretical teaching can be combined with experimental/practical teaching, and vivid and intuitive virtual simulation experiments can be introduced into the theoretical teaching process to avoid students from getting into the boring theoretical formula derivation at the beginning, which is beneficial to improve interest of students in learning.

In the course of theoretical classroom teaching, case teaching, heuristic teaching, and interactive (discussive) teaching can be conveniently used to fully motivate students' learning enthusiasm and inspire their curiosity, especially through interactive teaching, so that students can actively participate in In the teaching process, students and teachers form a harmonious and interactive relationship, allowing students to form a self-exploration learning model.

In the experimental teaching process, verification and cognitive experiments can be put into the basic experimental teaching process, and the virtual simulation experimental teaching platform can be completed by the students. Some of the verification and cognitive experiments can also be taught through virtual simulation. Integrate into the theoretical classroom teaching process to reduce this part of the experimental hours. Vigorously develop comprehensive experiments or research exploratory experiments and allow students to form learning habits of independent exploration through the provision of research exploratory experiments for students.

Introducing experimental projects such as discipline competition projects and engineering practical projects to allow students to further comprehend theoretical knowledge and integrate theory and practice through these highly specialized and highly sophisticated experimental projects. At the same time, due to the professionalism and complexity of the project, it requires students to form a team. During the exploration of the project, students need to work in a division of labor. Through a complete experimental project, students develop self-exploration and collaboration learning modes.

\section{Reform of Teaching Mode}

\section{1) Reform of teaching objectives}

The college revises three undergraduate major training programs. The original training goal was to train application-oriented senior engineering and technical talents, which now has been changed to "cultivating composite, applied, innovative advanced engineering and technical talents". The innovative ability has been added from the original focus on the cultivation of composite and applied talents.

\section{2) Reform of teaching curriculum setting}

The new syllabus compresses the credits and hours of each major, and at the same time the total credits are compressed, the number of points in practice is increased. According to the requirements of the new syllabus, the college organizes the teachers of the teaching and research section to revise the syllabus of each major, cut down the theoretical time, and increase the number of hours of experiment and practice. The establishment of a virtual simulation experimental teaching platform provided sufficient experimental projects and experimental platforms for the three majors. Experimental types are also changed from traditional single-validation experiments, comprehensive experiments, and design experiments to basic training-type experiments, improved training-type experiments, and innovative-type training experiments. The basic training type experiment is mainly to train basic operating skills of students; improval training type experiment to cultivate initiative and explore the research spirit of students; innovative training type experiment focuses on cultivating innovative thinking, collaboration spirit and comprehensive ability of students.

\section{3) Reform of teaching implementation process}

In the teaching process, the class is divided into groups to learn according to the teaching contents. Case teaching method, on-the-spot practice method, group discussion teaching method, and practice teaching method are generally adopted. Practical teaching methods targeted at discipline competition projects and engineering practice projects are encouraged and promoted. The specific practical teaching depends on the combination of laboratory equipment and virtual simulation experimental teaching platform, materialized teaching and virtual simulation teaching. In order to guarantee the quality of teaching and achieve the expectations of curriculum reform, the following teaching measures are adopted.

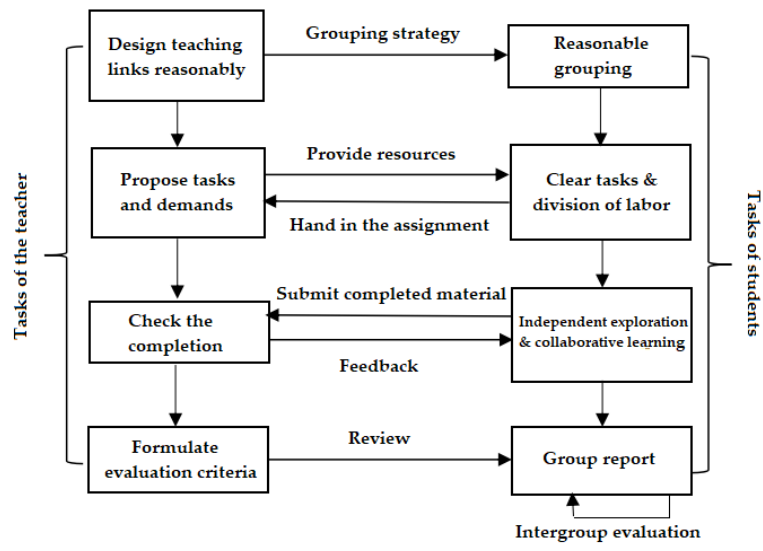

Fig.2 Teaching implementation process

\section{4) Reform of assessment methods}

The assessment of students adopts a full-process assessment method. The assessment runs through the entire learning process of students, take the data collection and arrangement of learning ability, problem-solving thinking and analysis ability, and physical operation ability as important indicators of assessment. At the same time, self-learning in the learning process (recording time of attendance, virtual simulation experimental teaching platform, etc.), exploratory learning (experiment design, recording of experimental process), collaborative learning (record of experimental process, presentation of results, etc.) are also included. Teacher makes a comprehensive evaluation of the comprehensive ability of each group of 
students by combining the experimental design, the recording of the experimental process, the completion of the experiment, and the final defense of the experiment. Through the combination of the whole monitoring mechanism and the final assessment, enthusiasm of students can be fully mobilized, make they participate in the course teaching and form a good interaction and effectively improve the teaching effect.

\section{CONCLUSIONS}

In order to cultivate high-quality composite, applied, and innovative senior engineering and technical talents, based on the virtual simulation experimental teaching platform and the cultivation of innovation ability, implement the teaching reform of the mechanical and electrical engineering major undergraduate course, build task-oriented and project-oriented projectized courses and student-oriented initiative, exploratory, and collaborative education and teaching models; cultivate awareness, habits, and abilities of self-learning, exploratory learning, and collaborative learning, and deepened for students; Deepened knowledge of the profession of students, improved their ability to apply professional knowledge and cultivated their innovative abilities.

\section{ACKNOWLEDGEMENT}

This work is supported by grants from Guangxi Higher Education Undergraduate Education Reform Project (No. 2016JGB236 and No. 2017JGB128).

\section{REFERENCES}

[1] He Kekang, Liuchunxuan. Teaching Model of the Integration of Information Technology and Curriculum (Sixth): JITT mode [J]. Modern education technology, 2008,12:9-13.

[2] Sun Xuan, Zhang Lieping, Zhong Zhixian, Li Haixia. Research and practice on the construction of virtual simulation experimental teaching center for mechanical and electrical engineering in local colleges and universities. 2018 2nd International Conference on Education, Culture and Social Development (ICECSD2018). 2018.5.Guilin, China.

[3] Yang Jianchao, Han Yafei, Wang Shengli. The ERP Course Autonomous Learning Teaching Model Reform Under Open Laboratory Platform $[\mathrm{J}]$. Research and Exploration in Laboratory. 2017.36 (5): 204-209. 